\title{
ASSESSING THE BENEFITS OF INTELLIGENT TRUCK PARKING
}

\author{
Jana Sochor* \\ PhD Candidate, KTH - Royal Institute of Technology \\ Transportation and Logistics Division, Teknikringen 72, SE-100 44 Stockholm, Sweden \\ tel +4687908010, fax +468212899, e-mail jana.sochor@abe.kth.se
}

\section{Gideon Mbiydzenyuy}

PhD Candidate, Blekinge Institute of Technology

Biblioteksgatan 4, SE-374 34 Karlshamn, Sweden

tel+4673422 3651, e-mail gideon.mbiydzenyuy@,bth.se

Pia Larsson

ITS Project Manager, Sweco

Gjörwellsgatan 22, Box 34044, SE-110 26 Stockholm, Sweden

tel +4686956369, fax +4686956370, pia.larsson@sweco.se

\begin{abstract}
The aim of this paper is to identify and provide a discussion about aspects related to benefits of Intelligent Truck Parking (ITP) for Heavy Goods Vehicles (HGVs) and their effects on different stakeholders. Most existing work has narrowly focused on benefits for private cars and does not include the user perspective. In this paper, a review of previous work helps identify benefit areas and stakeholder groups relevant for HGV transport. These benefit areas are then theoretically assessed and compared for different stakeholders. Additionally, interview results of Swedish drivers' and companies' perceptions of the ITP service are presented. Comparing results of the interviews with the theoretical assessment indicates that the end users may not perceive ITP as highly beneficial although they theoretically benefit the most. Companies, particularly national haulage companies, expressed a low willingness to pay for the service. The general conclusion is that the ITP service has a better chance of success as part of a package of services rather than as a stand-alone service.
\end{abstract}

\section{KEYWORDS}

Intelligent Truck Parking, heavy goods vehicles, stakeholder, user, benefit area, privacy, perceived safety, willingness to pay

\section{INTRODUCTION}

It has been estimated that to comply with working time directives, over $44 \%$ of journeys within international road freight transport require at least one rest (1). This implies that there is a high demand for parking infrastructure to accommodate the needs of different transport stakeholders, especially professional drivers. Intelligent Truck Parking (ITP), also known as Information on Truck Parking, is an Intelligent Transportation Systems (ITS) user service concerned with the management of information related to Heavy Goods Vehicle (HGV) parking operations. ITP collects data about parking facilities (services and availability), processes the data, e.g. occupancy level, and communicates the information to drivers (in real 
time) in order to help them easily access such a facility. ITP will enable efficient parking management and potentially improve the needs of transport stakeholders through the provision of information such as available parking spaces and additional services.

The EU directive 2010/40/EU emphasizes the need to develop ITP services across Europe through the provision of information and reservation services for safe and secure parking places for HGVs. Furthermore, ITP will facilitate electronic data exchange between road parking sites, centers and vehicles (2). Significant work has been accomplished through various EU-funded projects such as SETPOS (3) and LABEL (4). In Sweden, ITP is considered as one priority service for HGVs in the National ITS Action Plan (5). There are several projects underway that address various elements related to implementing ITP such as East West Transport Corridor II (6), ITS and Telematics: Different Implementation Aspects (7). The overarching aim of the project ITS and Telematics (7), results of which are partially presented in this paper, was to explore aspects of new, additional services, technical solutions, and integrity issues in relation to a potential position- and distance-based road user charging system for HGVs in Sweden. The two core services identified as having the greatest potential synergies were ITP and Incident Warning and were thus included as interview scenarios in the final phase of the project on end users' attitudes toward ITS services.

ITP can successfully be achieved if knowledge about benefits is shared among stakeholders. Currently it is unclear what benefits exist and for whom. Many studies have focused on addressing the evaluation of advanced parking management information systems for private cars $(8-11,26)$. A number of benefits have been reported including balancing the load for overcrowded parking facilities, reduction in waiting time before parking, reduction in illegal on-street parking, reduction in wandering vehicles, alleviation of traffic congestion, reduction in air pollution, and increased user convenience. Benefits have even been reported in the areas of travel times, distance, destination choice as well as influencing mode choice (8) in transit areas. As most of these advanced parking management systems were developed for city areas $(8,11)$, the support for long-distance HGV transport is limited. Indeed the knowledge about the benefits of ITP for HGV transport in general is limited and the degree to which the benefits will meet or exceed those identified for private cars. In addition, HGV transport requires dynamic and flexible management of parking information, and ITP anticipates addressing these needs. Initial assessments of ITP in Sweden indicate a possible reduction in the cost of missing and delayed goods and a reduction in time-based costs for HGVs (12). Potential stakeholder benefits of improved truck parking facilities have also been addressed in the project LABEL (4). However, most of the previous work has narrowly focused on certain specific benefit areas for private cars such as time savings, and does not take a comprehensive approach, e.g. little attention is paid to the user perspective or to the situation for HGVs.

The aim of this paper is to identify and provide extensive discussion about aspects related to benefits of ITP for HGVs and their effects on different stakeholders in society. This study differs from earlier work done in that it focuses on the benefits on a high level and attempts to identify the stakeholders accruing such benefits. In addition, this study presents interview data of the attitudes of Swedish professional HGV drivers and road haulage company representatives regarding integrity aspects of, perceived benefits of, and willingness to pay for the ITP service. The results of the interviews are compared with the literature-based theoretical assessment of the authors and indicate that the end users may not perceive ITP as highly beneficial although they theoretically benefit the most. By using both theoretical analysis of information from different sources and interviews of end users, a complementary and more comprehensive approach to assessing the potential benefits of ITP is presented. 


\section{METHODLOGY}

To identify ITP benefit areas, reviews of previous work related to ITP (such as 2-4, 12-13) and advanced parking management systems (such as 8,11 ) were conducted. A theoretical analysis helped identify potential stakeholders in the various benefit areas. Benefit areas were compared between stakeholders through an assessment and normalization process. The assessment was done by providing scores indicating if the benefit area will have a positive measurable effect, zero effect or negative measurable effect on the stakeholder group. The normalization was based on standard score or Z-score normalization, which compares the deviation from the mean value to the standard deviation. The reason for choosing this normalization was to be able to compare different benefits across different stakeholders while dealing with several variables.

In order to directly investigate the end users' attitudes, structured interviews via telephone were chosen. A self-administered questionnaire was considered, but judged to be a potential deterrent to recruitment as professional drivers might be reluctant to dedicate work breaks to such a task. In structured interviews, a quantitative data collection method, each respondent receives the same pre-determined questions in the same order and the questions often have a limited set of pre-determined responses. This consistency between individual structured interviews enables data aggregation and comparisons across respondents and time periods. Although context effects of question order cannot be completely eliminated, the nature of the structured interview holds these effects constant. As the number of respondents was expected to be limited, the time and labor costs were realistic. Even though structured interviews traditionally only allow for minimal responses, the interviewer did allow for respondents to elaborate if they so desired, with additional comments recorded by hand by the interviewer.

The data collected in the structured interviews was analyzed using PASW 18.0 for Macintosh. Due to the ordinal nature of the data (e.g. Likert Rating Scales of 1 to 5), non-parametric tests were used to test for significant differences $(\alpha=5 \%)$ : the Mann-Whitney U test compares differences between two independent groups (e.g. drivers' versus company representatives' answers to the same question) and the Wilcoxon Signed Rank test compares differences between two dependent groups (e.g. drivers' answers for two different questions). No significant differences were found in the interview data presented in this paper.

\section{POTENTIAL BENEFIT AREAS}

The following general benefit areas identified in the literature can be expected for ITP in the context of HGV transport. The extent to which such benefits are achieved will depend on the case under consideration. The areas identified below enable comparison and analysis of ITP benefits across regions and stakeholders.

\section{B1: Parking facility search time}

This includes the time taken to locate and drive to a parking area. It is commonly estimated that the manual search and location of parking in cities such as Stockholm can take up to 30 minutes for private cars and could account for $30 \%$ of traffic on roads (11), a situation which is even more time-consuming for HGVs due a relatively fewer number of parking spots. A driver using ITP will receive real-time, up-to-date, pre- and on-trip information, which enables them to know exactly which parking facility is available and for how long. Consequently, the time used in manually searching for such parking will be expected to 
decrease and hence benefit HGV drivers. In addition the driver will be provided with several choices that can improve his decision, which could eventually also decrease (depending on the traffic situation) the time used in driving to the parking. Experiences on search time savings have been reported in the United States (8) and the United Kingdom (14). In the case of reduced driving time, minor benefits in fuel consumption and vehicle depreciation will likely be achieved. A reduction in time for locating and driving to parking should improve the flow of traffic and hence benefits traffic controllers. Parking infrastructure users will likely experience better utilization because drivers should be able to easily locate parking facilities. The availability of parking information has been shown to reduce queue times and travel times for private cars (10).

\section{B2: Parking-related theft and insecurity}

The Swedish National Council for Crime Prevention (BRA) reports a steady decrease in the number of vehicle-related crimes over the last decade (15). Most of these crimes, however, continue to occur in parking areas. A number of reported theft cases in parking areas take place at inappropriate parking locations, which results in loss and damage to HGVs and their contents. ITP has the potential to minimize these cases using geo-fencing capabilities, which allow information about unauthorized intrusion to be communicated quickly to the appropriate authorities. The use of surveillance cameras alone indicates that it is possible to reduce vehicle-related crimes in parking up to 51\% (27). Improving security in parking areas has been shown to lead to a better work lifestyle, fewer dangers and help in informed decision making for drivers (13). Road haulage companies and goods owners primarily benefit from improved security at parking areas, and the risks facing drivers should also decrease.

\section{B3: Accidents as a result of roadside parking}

Generally, inappropriate roadside parking has increased in Europe due to regulations limiting the number of driving hours (16). Statistics from the Swedish Enforcement Agency (Kronofogden-debt collection agency) indicate $45 \%$ of debt cases in 2008 were related to fines for illegal parking (primarily on roadsides), amounting to a total cost of 47.3 million Euros for car owners (17). The major cause of illegal parking is lack of information about parking. For HGV drivers to avoid exceeding their maximum number of driving hours, drivers are forced to park on roadsides. Such parking has resulted in accidents from incoming traffic. Studies show that street parking (private cars) accounts for about $10 \%$ of accidents occurring in such areas (18). One benefit of an ITP service will likely be to reduce such accidents. Reducing accidents should improve operations for a wide range of stakeholders including drivers, road haulage companies, goods owners and road users.

B4: Accidents as a result of fatigue from excessive driving time The driving task demands high concentration from the driver throughout the entire trip. The driver may get tired and, thus, should rest before continuing the trip. An HGV driver who avoids illegal parking (as in B3 above) and continues to drive will find himself not just exceeding the driving time limit, but also likely to suffer from fatigue. Such situations are said to account for up to 100,000 accidents per year worldwide and $25 \%$ of all road accidents in Sweden (19). Providing the driver with information to enable better trip planning can reduce these accidents. Reducing fatigue-related accidents also benefits road haulage companies, goods owners, road users and traffic controllers.

\section{B5: Utilization of parking facilities}

Due to lack of information about the availability and status of parking facilities, such facilities may be underutilized. HGV drivers turn to parking in unauthorized areas due to lack of 
adequate information about parking, leading to problems such as shoulder damage, restriction of sight, litter, noise, etc (20). Sharing information about parking facilities can generally lead to better utilization of such facilities. Implementation of transit parking information service in the United States shows an increase in parking utilization $(8,21)$. This will primarily benefit the parking infrastructure owners.

\section{B6: New business for Telematic Service Providers (TSPs)}

A successful implementation of ITP will be based on good business models. Such models benefit the TSPs, parking infrastructure owners and society in the form of employment.

\section{B7: Perceived safety}

Access to information enhances perceived safety and security by lowering stress and uncertainty for the driver, particularly along unfamiliar routes. ITP information, such as parking availability and additional services offered in the vicinity of the parking area, enables the driver to both plan ahead and deal with unforeseen circumstances, which also increases the efficiency of the driving task (including stops and rest periods) and lowers stress. The knowledge that the goods are securely parked also increases the perceived safety and security on the parts of the drivers, haulage companies, and goods owners.

\section{B8: Potential use as re-charging stations for hybrid vehicles}

With increasing interest in clean energy sources, the possibility of electric-powered trucks cannot be completely overruled (22). With hybrid trucks that depend on electricity for fuel, it will be crucial to have access to accurate, up-to-date information about parking facilities and available recharging services. ITP can facilitate the move toward electric-powered trucks by managing the required time for charging and the available time for parking. The duration of charging is one aspect being considered in the development of components for charging electric vehicles (23).

\section{B9: Potentially lower insurance premiums}

One overall benefit that will accrue from providing ITP is a clear mechanism of transferring responsibilities for goods and vehicles, depending on the level of security of the parking facility (24). Added to an expected reduction in theft cases (B2) and accidents (B3), it can be expected that insurance premiums will likely decrease. This will create additional benefits for haulage companies and goods owners.

In addition to the above main direct benefits, indirect benefits can be taken into consideration, e.g. improved security will likely lead to fewer incidents and hence a company's reputation may be improved, which may also lead to increased revenue through increased contract wins (25). It is important to point out that the anticipated benefits for ITP discussed above are dependent on the type of services that are implemented together with ITP (assuming they are also used), e.g. Navigation and ITP will not lead to the same benefits as Intelligent Speed Adaptation and ITP (12).

\section{THEORETICAL ASSESSMENT RESULTS}

Various stakeholders ranging from HGV drivers to parking infrastructure owners will potentially be influenced by the introduction of ITP. A theoretical assessment of potential benefits for different stakeholders is provided based the authors' interpretation of the literature. These assessments are then normalized using the standard Student test in order to 
facilitate their comparison (Figure 1). We consider three possible effects of benefits including:

$\mathrm{X}$ : Main benefits will not lead to any observable change

$€$ : Main benefits will lead to a quantifiable positive change

$\odot$ : Main benefits will lead to a non-quantifiable positive change

Using the above symbols we make a preliminary assessment of the benefit areas for different stakeholders, as shown in Table 1. Multiple symbols indicate a greater potential benefit.

\begin{tabular}{|l|c|c|c|c|c|c|c|}
\hline Benefit & \multicolumn{8}{|c|}{ Stakeholder } \\
\hline & TSP & Drivers & $\begin{array}{c}\text { Road haulage } \\
\text { companies }\end{array}$ & $\begin{array}{c}\text { Goods } \\
\text { owners }\end{array}$ & $\begin{array}{c}\text { Parking inf. } \\
\text { owners }\end{array}$ & $\begin{array}{c}\text { Road } \\
\text { users }\end{array}$ & $\begin{array}{c}\text { Traffic } \\
\text { controllers }\end{array}$ \\
\hline B1 & $\mathrm{X}$ & $€ € €$ & $€$ & $\mathrm{X}$ & $€$ & $\mathrm{X}$ & $€$ \\
\hline B2 & $\mathrm{X}$ & $€ €$ & $€ €$ & $€ €$ & $\odot$ & $\mathrm{X}$ & $\mathrm{X}$ \\
\hline B3 & $\mathrm{X}$ & $€ €$ & $€$ & $€$ & $\mathrm{X}$ & $€$ & $\mathrm{X}$ \\
\hline B4 & $\mathrm{X}$ & $€ € €$ & $€$ & $€$ & $\mathrm{X}$ & $€$ & $€ €$ \\
\hline B5 & $\mathrm{X}$ & $\mathrm{X}$ & $\mathrm{X}$ & $\mathrm{X}$ & $€ €$ & $\mathrm{X}$ & $\mathrm{X}$ \\
\hline B6 & $€ € €$ & $\mathrm{X}$ & $\odot$ & $\mathrm{X}$ & $€$ & $\mathrm{X}$ & $\mathrm{X}$ \\
\hline B7 & $\mathrm{X}$ & $\odot$ & $\odot$ & $\odot$ & $\mathrm{X}$ & $\mathrm{X}$ & $\mathrm{X}$ \\
\hline B8 & $\mathrm{X}$ & $\odot$ & $€$ & $\mathrm{X}$ & $€$ & $\mathrm{X}$ & $\mathrm{X}$ \\
\hline B9 & $\mathrm{X}$ & $\mathrm{X}$ & $€ €$ & $€$ & $\mathrm{X}$ & $\mathrm{X}$ & $\mathrm{X}$ \\
\hline
\end{tabular}

Table 1: Benefits for different stakeholders

The normalization process considers the following: $€=1, \odot=0.5$ and $X=0$. Replacing the above estimate with the suggested weights, the standard score normalization or Z-score is then employed and the results obtained are shown in Figure 1.

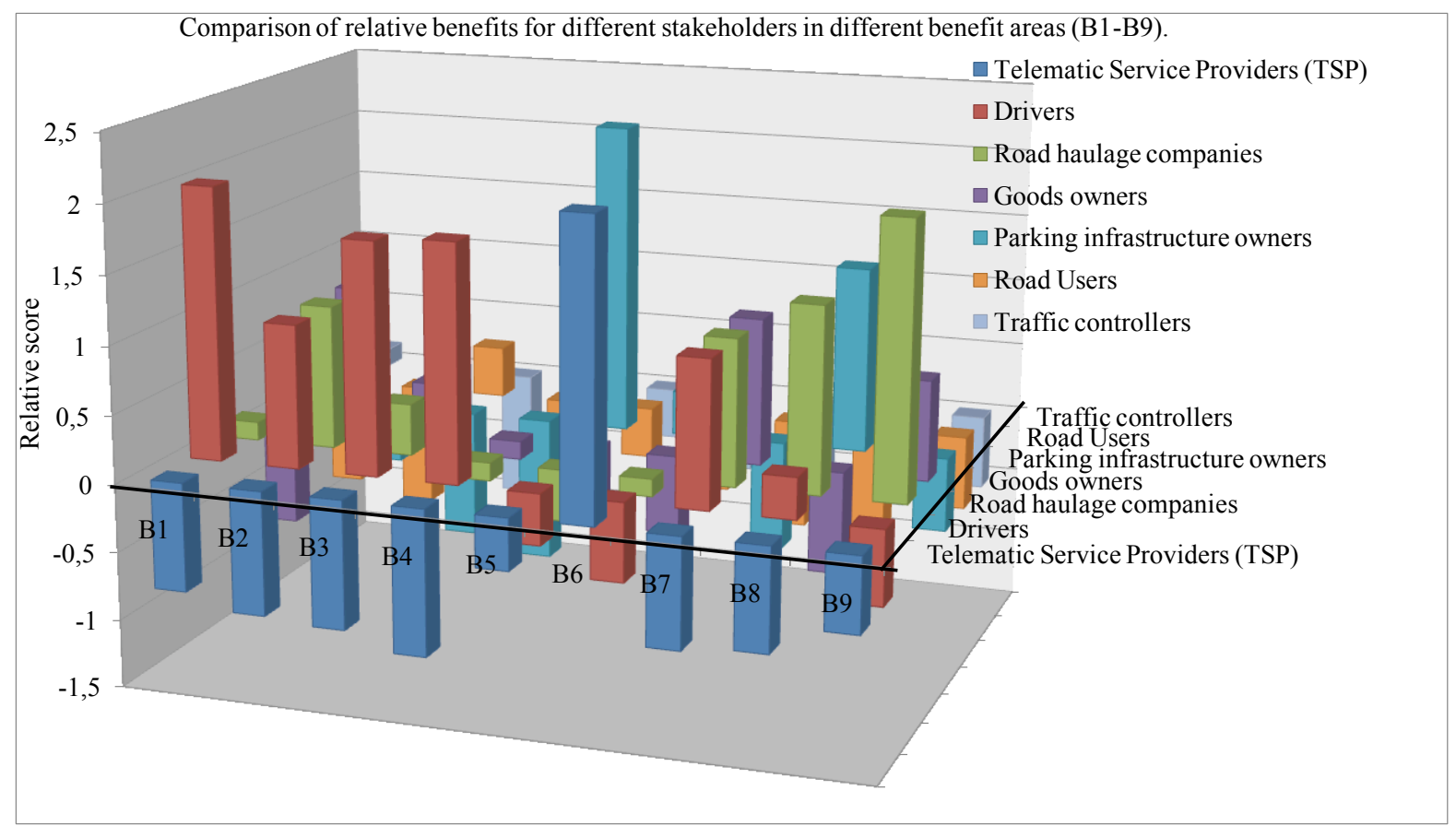

Figure 1: ITP assessment of benefit scores for different stakeholders

Note the variation of the relative comparison is from negative to positive due to the normalization process. The comparisons above indicate that drivers will be the leading beneficiaries of the ITP service; followed by the road haulage companies, goods owners, 
parking infrastructure owners, traffic controllers, TSPs and road users. Since the results of the comparison depend much on the value of the weights associated with the benefits, such results need to be interpreted with care. However, we believe that the results of the comparison are early indications of some of the ITP benefits and their respective beneficiaries. One way to complement such an approach is to ask the end users themselves about their perspectives on the ITP service. Do the drivers and road haulage companies see themselves as benefitting from the ITP service?

\section{INTERVIEW RESULTS}

Fifty participants were recruited via contact with Sveriges Åkerier (a Swedish trade organization of road haulage companies), contacts with service providers, and Internet searches. The 19 companies who agreed to participate in the study were spread throughout Sweden and represented many types of haulage companies, from international and national long-distance haulage companies to regional delivery and distribution. A total of 50 structured interviews were completed via telephone in the fall of 2010 , including interviews with 30 drivers from 13 companies and with 20 company representatives from 19 companies (two regional branches from one of the companies participated). Of the company representatives, 13 identified their companies as primarily national haulers and seven as international. The company representatives themselves included owners, traffic planners, project leaders, various managers, etc. Table 2 provides a key of symbols and overview of the socio-demographic characteristics of the participants.

\begin{tabular}{lll} 
Key of Symbols & & \\
\hline $\begin{array}{l}\bar{x}=\text { mean } \\
\tilde{x}=\text { median }\end{array}$ & $\begin{array}{l}\mathrm{s}=\text { standard deviation } \\
{[\mathrm{min}, \mathrm{max}]=\text { range }}\end{array}$ & \\
\hline Demographic & Driver & Company Representative \\
\hline Type of Participant & 30 & 20 \\
\hline $\begin{array}{l}\text { Gender } \\
\text { Age }\end{array}$ & 29 male +1 female & 17 male +3 female \\
\hline Years of Driving Experience & $\bar{x}=44.2,[20,66]$ & $\bar{x}=43.9,[20,64], \mathrm{n}=17$ \\
\hline Years at Current Company & $\bar{x}=11.2,[0.5,42]$ & $\overline{\mathrm{n}}=12$ with $\bar{x}=13.75,[2,30]$, \\
\hline
\end{tabular}

Table 2: Key of symbols and socio-demographic characteristics of participants

The ITP scenario in the interview described ITP as follows: "The service aims to create systems for information about, management of, and booking of truck parking. It will inform the driver about current parking areas for trucks, if the parking area is monitored, the availability of additional services in the vicinity, and the possibility of booking a spot. The truck parking areas along the road as well as their occupancy levels and services will be seen on the on-board unit in the vehicle and the driver will then have the possibility to plan ahead and book a vacant place via the on-board unit. The driver can then better plan his stops in order to better utilize his time. This also means that the trucking company knows the locations of their drivers while resting, and that the owner and operator of the truck parking area knows where the drivers are and what goods they are carrying."

The ITP scenario also contained four rating questions (with one additional question for the company representatives): 
- One question each about how the participant thought this service would affect the driver's sense of perceived safety and privacy, respectively (using a Likert Rating Scale of 1 to 5 where $1=$ Very Negatively and $5=$ Very Positively);

- One question each about how much the participant thought this service would benefit the drivers and company, respectively (using a Likert Rating Scale of 1 to 5 where $1=$ Totally Disagree and 5 = Totally Agree);

- One additional question for the company representatives about how much they thought the service would be worth in Swedish kronor per month and per vehicle.

The participants' responses to the questions in the ITP scenario are as follows:

\section{Question: How do you think that the driver's sense of perceived safety would be affected by this [ITP] service?}

Overall: $\bar{x}=4.16(s=0.980), \tilde{x}=4$

Drivers: $\bar{x}=4.07(s=0.179), \tilde{x}=4$

Companies: $\bar{x}=4.30(s=0.733), \tilde{x}=4$

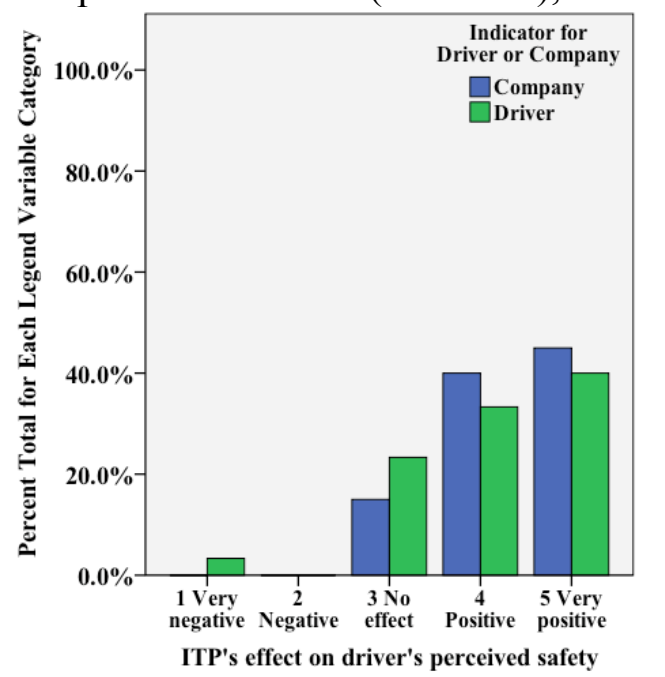

Figure 2: ITP's effect on perceived safety
Question: How do you think that the driver's sense of privacy would be affected by this [ITP] service?

Overall: $\bar{x}=3.08(s=0.528), \tilde{x}=3$

Drivers: $\bar{x}=3.10(s=0.481), \tilde{x}=3$

Companies: $\bar{x}=3.05(s=0.605), \tilde{x}=3$

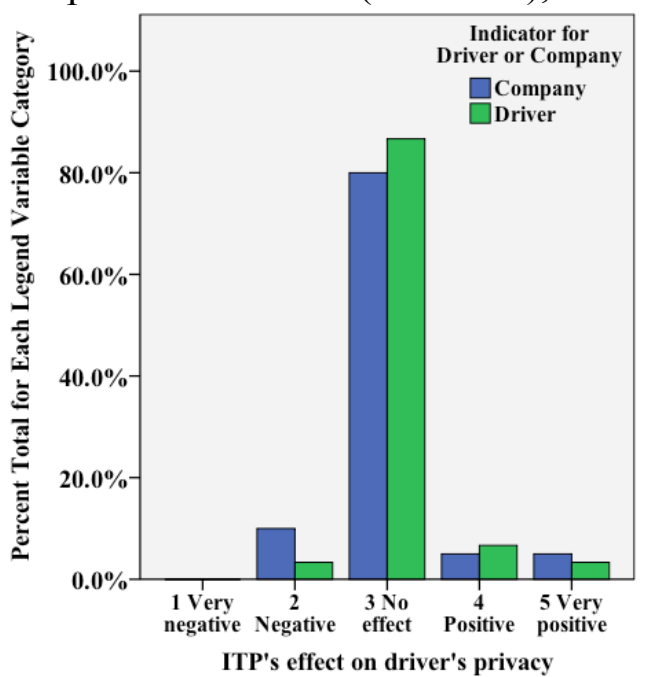

Figure 3: ITP's effect on privacy

Both drivers and company representatives feel that ITP would have a positive effect on the driver's perceived safety ("trygghet" in Swedish, which encompasses the concepts of perceived safety and security as well as connotations of confidence and comfort). When considering the positive and very positive ratings, a clear majority of drivers $(73 \%)$ and company representatives $(85 \%)$ perceive a positive effect, benefitting the driver. Despite the general agreement that ITP would have a (very) positive effect, two drivers did express concerns over becoming potential targets as criminals may assume that trucks parked at "safe" areas must be carrying valuable cargo.

When formulating the interview questions, we also wished to know if there was a perceived trade-off between safety and privacy when using various ITS services, where one accepts less of one in order to gain more of the other. In the case of ITP, there is no evidence supporting the existence of perceived trade-off of increasing safety perceptions at the expense of privacy as both the drivers and company representatives clearly feel that the ITP service will have no effects on the driver's sense of privacy. Similar results were found in the section of the interview concerning general integrity in the workplace when asking rating questions on the effect of being able to locate a vehicle in real time on the driver's sense of privacy, and on the 
effect of being able to reconstruct driver behavior with the help of vehicle data on the driver's sense of privacy.

Technically, the Swedish language does not include the word "privacy." In the interview, the closest equivalent Swedish phrase "personlig integritet" was used, which directly translates to "personal integrity." This phrase is potentially problematic as integrity has many connotations, such as honesty, trust, justice, control, dignity, autonomy, etc., which may explain the few answers indicating that the ITP service would have a positive effect on drivers' privacy even though it is not a privacy-enhancing service. As some participants pointed out, having vehicle data showing locations, times, and behavior can be an advantage for the drivers and companies in that it can be used to settle disputes or to make drivers aware of how to improve their driving style, e.g. staying within the speed limits, eco-driving, etc. In the case of ITP, being able to prove you were at a certain parking area at a certain time may enhance your "integrity" in the sense that it serves as evidence of your honesty.

\section{Statement: I think the drivers would benefit a lot by having this [ITP] service in their vehicles.}

Overall: $\bar{x}=3.08(s=1.652), \tilde{x}=3.5$

Drivers: $\bar{x}=3.00(s=1.661), \tilde{x}=3$

Companies: $\bar{x}=3.20(s=1.673), \tilde{x}=4$

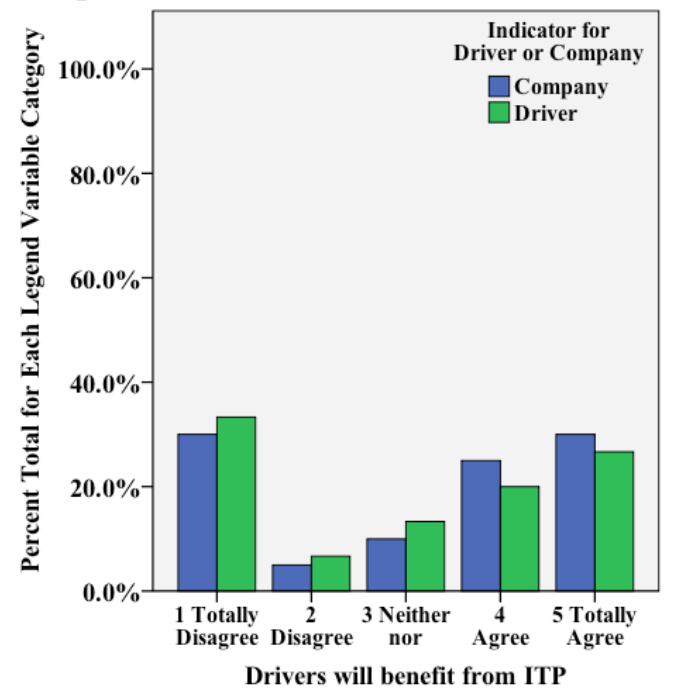

Figure 4: The drivers will benefit from ITP
Statement: I think the company would benefit a lot by having this [ITP] service in their vehicles.

Overall: $\bar{x}=3.34(s=1.560), \tilde{x}=4$

Drivers: $\bar{x}=3.47(s=1.432), \tilde{x}=4$

Companies: $\bar{x}=3.15(s=1.755), \tilde{x}=3.5$

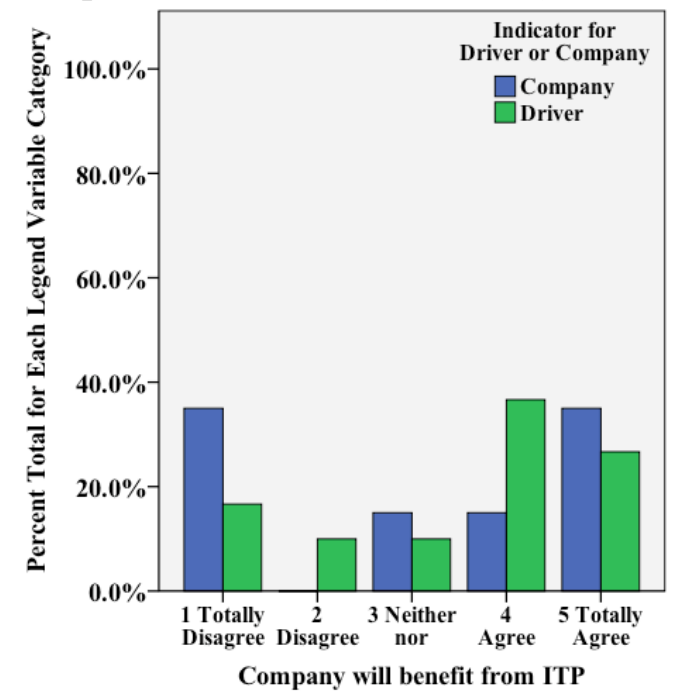

Figure 5: The company will benefit from ITP

Although increased perceived safety is clearly beneficial to drivers, the interview also included questions about the ITP service's general benefit to drivers and companies, respectively. On average, the perceptions of benefit to the driver were neutral and the perceptions of benefit to the company were slightly positive. Although the drivers' perceptions of benefits differed the most (with the company benefits higher), there was no significant difference between how each group rated the benefits to both their own group and to the other group. The slightly higher perceived benefit for the company may reflect the possibility for ITP to ensure a higher level of security for the road hauler's customers and goods carried. Multiple participants mentioned that the use of secure parking is highly influenced by the customers' demands and type of goods to be delivered.

Regarding the neutral benefit of the ITP service for the drivers, the results of this question may appear to contradict the earlier results indicating a positive effect of the ITP service on 
drivers' perceived safety. In this case, the positive effect on perceived safety does not directly translate to a perception of overall benefit. Why this is so is difficult to determine, but may be due to an already sufficient base level of perceived safety, in which case an improvement would be more of a bonus than a necessity. Also, perceived safety is only one of the possible benefits of ITP, as discussed above, and the end users may not prioritize it as highly as other benefits. This illustrates the importance of asking complementary questions in order to paint a more complete picture of users' attitudes. As seen from the next question, a positive impact on perceived safety will not either translate into a high willingness to pay.

\section{Question: How much do you think that the ITP service is worth in Swedish kronor per month and vehicle?}

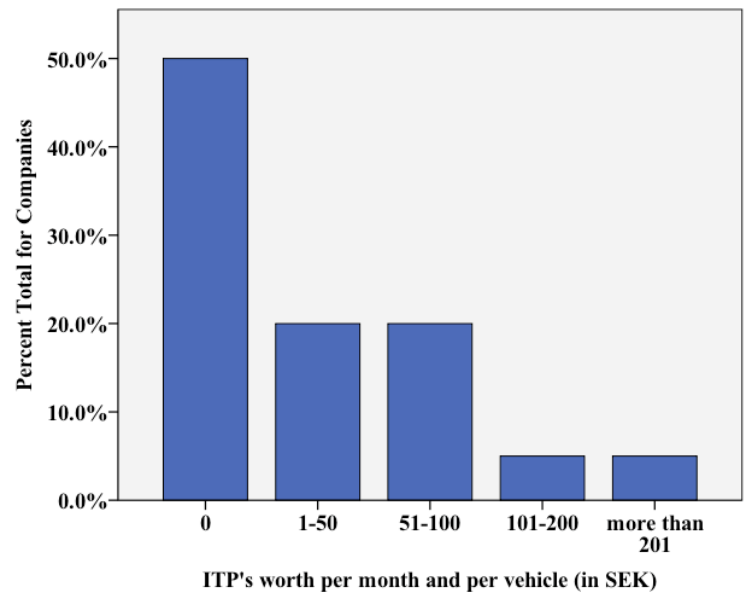

Figure 6: ITP's estimated worth per month and vehicle (in SEK)

The neutral to slightly positive perceived benefits to the drivers and companies, respectively, translate into a low willingness-to pay on the part of the companies. Half of the company representatives stated that they were not willing to pay anything at all (per month and vehicle) for the ITP service. One company representative commented that there is, in general, no margin for extra costs in the haulage sector. Another commented that they would be willing to pay to park at a parking area, but they wouldn't be willing to pay for information about such an area or for booking a parking place at it, analogous to an individual finding and booking versus paying to sleep in a hotel. It should be noted, however, that $80 \%$ of those not willing to pay had identified themselves as primarily national haulers. Considering that one representative and two drivers added that the ITP service was much more relevant for international or night trips than for regular, urban, or national trips, this could partially explain the national haulers' lower willingness to pay.

Of those company representatives (half national haulers and half international) willing to pay for the ITP service, $20 \%$ stated they were willing to pay up to 50 SEK and $20 \%$ between 50 and 100 SEK ( $€ 1$ is worth just over 9 SEK as of August 2011). Assuming these $50 \%$ of companies willing to pay are representative of the Swedish HGV fleet (i.e. half of the approximately 65,000 vehicles will have the service), and assuming a revenue estimate of $€ 5$ per vehicle per month (which falls in the lowest positive category), the annual revenue amounts to 1.95 million Euros. This is far less than the cost estimate for nationwide deployment (49.16 million Euros) in Sweden (12), which suggests that the information side of the ITP service has a better chance of success as part of a package of services rather than as a stand-alone service, thus further pointing to the need for developing ITP on shared infrastructure or multi-service architectures. 


\section{CONCLUSIONS AND FURTHER WORK}

The deconstruction of ITP benefit areas and stakeholder groups carried out in this article provides preliminary steps toward a comprehensive assessment and analysis of ITP benefits. The paper identifies main benefit areas for ITP and suggests a theoretical analysis of such benefit areas. The results of the theoretical analysis indicate that drivers and road haulage companies, followed by goods owners and parking infrastructure owners, will benefit the most from the implementation of an ITP service. Interviews investigating the drivers' and companies' attitudes towards the ITP service indicate that ITP will contribute to the drivers' perceived safety and not invade their privacy. Additionally, the benefit for the company was perceived as slightly positive, and marginally higher than the benefit for the drivers (neutral benefit). This also translated into a low willingness to pay on the part of the companies, especially by national haulage companies, the majority of which were not willing to pay anything for the ITP service. Based on the company representatives' estimates of the worth of the ITP service, the annual revenue is approximated at 1.95 million Euros, which is significantly lower than the initial implementation cost. The general conclusion is that the ITP service has a better chance of success as part of a package of services rather than as a stand-alone service, thus further pointing to the need for developing ITP on shared infrastructure or multi-service architectures. Further work could include quantifying the suggested benefit areas for a defined case. Also, all stakeholder groups could be included in an in-depth analysis, e.g. via a more theoretical Delphi study relying on a panel of experts or interviews focused only on the ITP service, which would allow for a more thorough exploration of the stakeholders' perceptions.

\section{ACKNOWLEDGEMENTS}

We wish to thank ITS Sweden and the Swedish National ITS Postgraduate School, Vinnova (The Swedish Governmental Agency for Innovation Systems), and Trafikverket (The Swedish Transportation Administration) for funding this research.

\section{REFERENCES}

(1) SETPOS, Secured European Truck Parking Best Practice Handbook, 2009. http://www.setpos.eu/handbook/SETPOS-project-handbook.pdf last access 2011-08-03.

(2) Stephanie Kleine, Rheinland-Pfalz, Karina Runte, "Guideline for the deployment of Intelligent Truck Parking Core European ITS Services and Actions", published by the EasyWay Project, 2010.

(3) SETPOS (Secure European Truck Parking Operational Services) project website, http://www.setpos.eu/about_setpos.htm last accessed 2011-02-11.

(4) LABEL (The European Truck Parking Area LABEL Project) project website, http://truckparkinglabel.eu/ last accessed 2011-02-11.

(5) Marie-Louise Lundgren, “Trafikslagsövergripande Strategi och handlingsplan för användning av ITS”, ISSN: 1401-9612, Trafikverket, 2010.

(6) Christian Udin, Jens Löfgren, Marie Karlsson, "Truck Parking Strategy for the East West Transport Corridor", WP6D Truck Stops with ITS - Activity 1, 2011.

(7) Thomas Sjöström, Pia Larsson, Jana Sochor, Christian Udin, Isak Jarlebring, "Marknadsmässiga aspekter kring positionsbaserad ITS" [ITS and Telematics: Different Implementation Aspects], Trafikverket [Swedish Transportation Administration], 2010. 
(8) J. Rephlo (SAIC), R. Haas L. Feast D. Newton, "Evaluation of Transit Applications of Advanced Parking Management Systems" Final Evaluation Report, US DOT Federal Transit Administration FTA, Report Number FTA-TRI-11-2008.1

(9) T3 Design, Automated Parking Information System Operational Test Evaluation, WMATA Glenmont Parking Facility, Report Number FTA-MD-26-7021.2010.01

(10) Russell G. Thompson, Kunimichi Takadab and Saturo Kobayakawa, "Optimisation of parking guidance and information systems display configurations", Transportation Research Part C: Emerging Technologies, Vol. 9, Issue 1, February 2001, pp 69-85.

(11) Anthony D. May, “Transport strategy. A decision maker's guidebook / Policy and instruments / Parking guidance information systems". Based on PROSPECT -Procedures for Recommending Optimal Sustainable Planning of European City Transport Systems (1999-2005). Ed. University of Leeds, LS2 9JT, 2005.

(12) Gideon Mbiydzenyuy, "Assessment of telematic systems for road freight transport", Licentiate Dissertation Series No. 2010:10, published by Blekinge Institute of Technology, 2011.

(13) "Handbook for Labelling / Security and Service at Truck Parking Areas along the TransEuropean Road Network", EU Directorate General for Mobility and transport, 2010.

(14) UK DfT, "Understanding the Benefits and Costs of Intelligent Transport Systems: A Toolkit Approach", 2011. http://www.dft.gov.uk/itstoolkit/ last accessed 2011-02-11.

(15) BRÅ, "Säkrare parkeringsplatser! Handbok med checklista, som hjälper dig att förebygga bilbrott", Brottsförebyggande rådet (BRÅ), ISBN 91-38-32130-0, 2004.

(16) Rainer Lehmann, Jessica Kleine, "ITP pilots in Germany and the Intelligent Compact Parking", Bundesanstalt für Straßenwesen Federal Highway Research Institute, ITP workshop, August 2010.

(17) Transportstyrelsen, "Förslag till åtgärder för minskning av restförda fordonsrelaterade skulder och för att motverka användningen av bilmålvakter", TSV 2009:8959 KFM 808 21617-08/123, May 2009.

(18) Tyréns AB, “Kantstensparkering - hur trafiksäkert är det?", December 2010.

(19) NORDIC, "Fatigue in traffic" Road and transport research, NORDIC, No 2, 2008. http://www.nordicroads.com last accessed 2011-08-03.

(20) NCHRP, "Dealing with Truck Parking Demands. A Synthesis of Highway Practice", National Corporative Highway Research Program, Synthesis 317, 2003.

(21) Anders Lindkvist, Peter Kronborg, Niklas Carlsson, Emma Hermansson, "ITS för parkering - behov och potential”, Vägverket, 2003.

(22) Hanna Baker, Richard Cornwell, Enrico Koehler, Jane Pattersson, "Review of Low Carbon Technologies for Heavy Goods Vehicles", Prepared for DfT by Ricardo, RD.09/182601.7, March 2010.

(23) C. C. Chan, and K. T. Chau, "An Overview of Power Electronics in Electric Vehicles", IEEE Transactions on Industrial Electronics, Vol. 44, No. 1, February 1997, pp 3-13.

(24) Bern Grush, "Optimizing GNSS-Based Mobility Pricing for Road-Use, Parking and PayAs-You-Drive Insurance", 4th European Traffic Congress, Salzburg, 2005.

(25) DfT, "Strategy for Lorry Parking Provision in England", 2009. http://www.dft.gov.uk/pgr/freight/road/lorryparking.pdf last accessed 2011-02-11.

(26) SAIC, "Advanced Parking Management Systems: A Cross-Cutting Study - Taking the Stress Out of Parking", U.S. DOT Federal Highway Administration, EDL Number 14318, Report Number. FHWA-JPO-07-011, January 2007.

(27) Brandon C. Welsh, David P. Farrington, "Kameraövervakning och brottsprevention En systematisk forskningsgenomgång”, BRÅ publication number 978-91-85664-85-6, 2008. 